Earth \& Environment | Roland Werchota

\title{
Urban water and sanitation reforms in Sub-Saharan Africa
}

Many countries in the developing world have of their urban water and sanitation. Unfortunately, few have achieved excellent, sustainable results. In his recent book, 'Empty Buckets and Overflowing Pits', Dr his research into urban water and sanitation sector reform in four Sub-Saharan African countries, Burkina Faso, Kenya, Tanzania and Zambia, and explains why these endeavours accomplish such varied results. He argues that a standardised reform process is unlikely to be successful and recommends that six crucial factors in order to succeed.

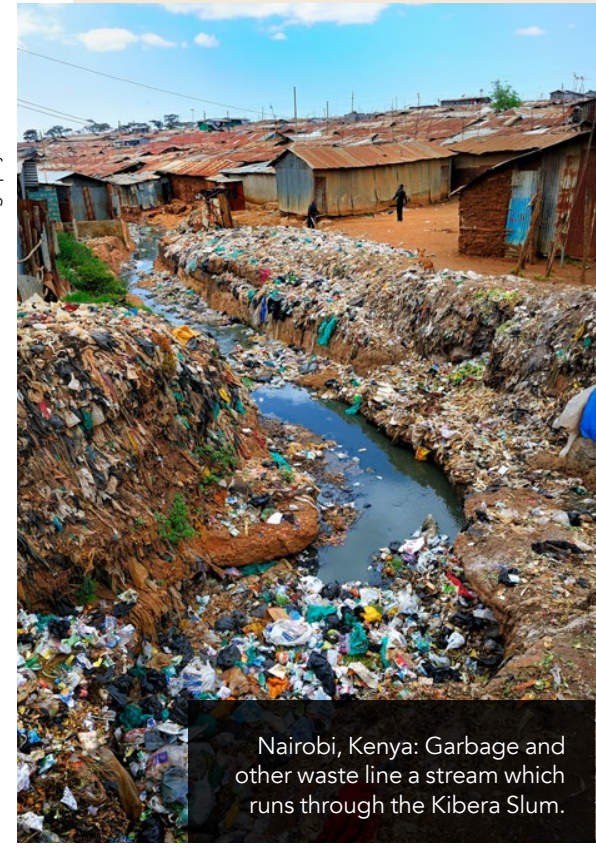

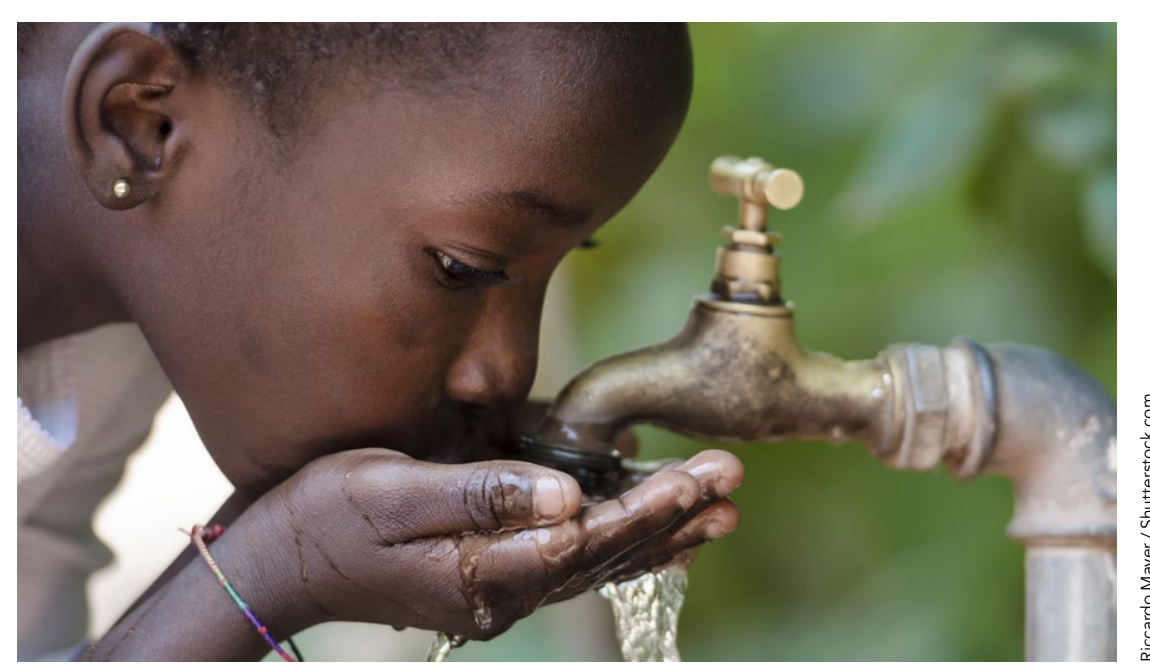

ccess to clean water and sound sanitation services are vital for
the survival of human beings. hese services are even more critical than housing, education, or electricity. They are crucial for human survival, especially in the rapidlly expanding urban settings 'Empteveloping countries. In his new book, 'Empty Buckets and Overflowing Pits', Roland Werchota shares his analysis of sector reform that focuses on SubSaharan Afica, identifying the factors and sanitation services.

\section{CLEAN WATER AND}

SAFE SANITATION

Globally, half of the urban population in income areas and slums under deplorable conditions. In today's world, 690 million people go to bed hungry but almost 2 billion have to consume contaminated water and use inhuman and dangerous sanitation infrastructure every day. Roland Werchota explains how, within generation, the benefits generated by access to clean water and safe sanitation in relation to health, productivity, dignity and gender equality can outstrip the cost of the infastructure development required to provide water and sanitation,
securing public health and enabling urban when national leaders declare a state of . ye\% of meoplong claims that over in the same country For decades, the gral targets for water and sant access, including the water MDGs Millennium Development Goals have filed to materialise. Furthermore, dat indicate that the water and sanitation SDGs (Sustainable Development Goals) will not be met.

While there are many reasons for these failures, key causes lie with the decisio makers' and experts' lack of experience in water and sanitation development, as well as the JMP's definition of water and sanitation access that contravenes he minimum requirements of human nights. The erroneous messages from investment exacerbate the chronic in the unnecssan deaths of hundrods of thousands of children as well as a billion people being stuck under or near the poverty line DrWerchota observes that "the link between access to water and sanitation and poverty is not sufficiently recognised in practice and the suffering due to insufficient access is still too silent"

\section{SECTOR REFORMS IN}

LOW-INCOME COUNTRIES

Many countries in the developing world

have undertaken ambitious reforms

of their urban water and sanitation.

The majority have had substantial help from the international cooperation. excellent sustanabu achicu out why these ende results. To find uch varied results, Roland Werchota has undertaken research into urban water and sanitation sector reforms in four SubSaharan African countries: Burkina Faso, Kenya, Tanzania and Zambia.

The research objective was to identify the fundamental factors for the sector's development along with the principles required for an effective sector

orientation and then test them in the four countries. In addition to collecting utility performance and investment data, Dr Werchota completed a detall document analysis about the sector framework and its development and performed extensive expert interviews of the major players and consumer groups measure access in different ways so developed to produch mues were be compred across the four councould well as the global monitoring data.

\section{RESULTING BENEFITS}

AND DETRIMENTS

DrWerchota's latest book details the water sector reforms and the fundament changes reached in each of the four target countries. The most noteworthy results are that the state institutions have started to pay their water bills regularly and there are movements towards making consumers costs. The regulation of utility senvices costs. The regulation of utility services has the implementation of consumer rights On the other hand, professionalisation is incomplete, particularly in the areas mobilisation and sanitation development. It was also noted that there is not enough resilience against undue politica interference. Consequently, the sector remains unstable. As an example, Tanzania, although benefitting from a huge investment programme (almost three times the amount per capita spent compared with Kenya and Zambia), was unable to stop the negative trend in access and its performance lags behind the other countries.

access to clean water and a sound

sanitation chain is still too silent.

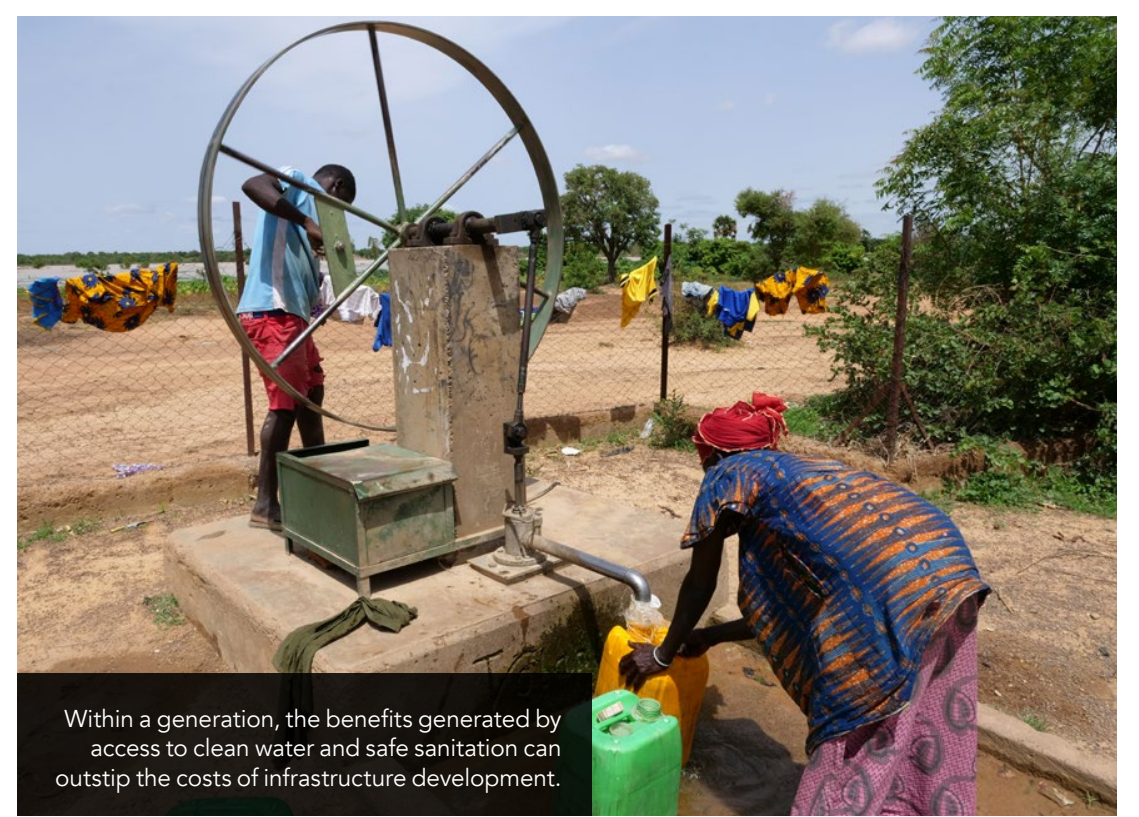


